\title{
Trial of a 'Webinar' to improve student perception of engagement
}

\section{Paul Stoneman}

Faculty of Business, University of Greenwich

\section{Introduction}

A group of part-time students studying the MBA in a blended mode of both online facilitated learning and face-to-face workshops had commented that they felt like second-class citizens in comparison to their full-time counterparts. A number of academics agreed to trial 'Adobe Connect' as a means of enhancing engagement for both part-time and full-time participants.

\section{What is it?}

Adobe Connect is a hosted (one does not need a server to store content) web-based application for running online seminars - commonly known as 'webinars'.

\section{What can it do?}

Adobe Connect webinars allows groups to share multi-media in real-time whilst recording it to playback later.

Figure 1: Screenshot of Adobe Connect Webinar's main screen (March 2013)

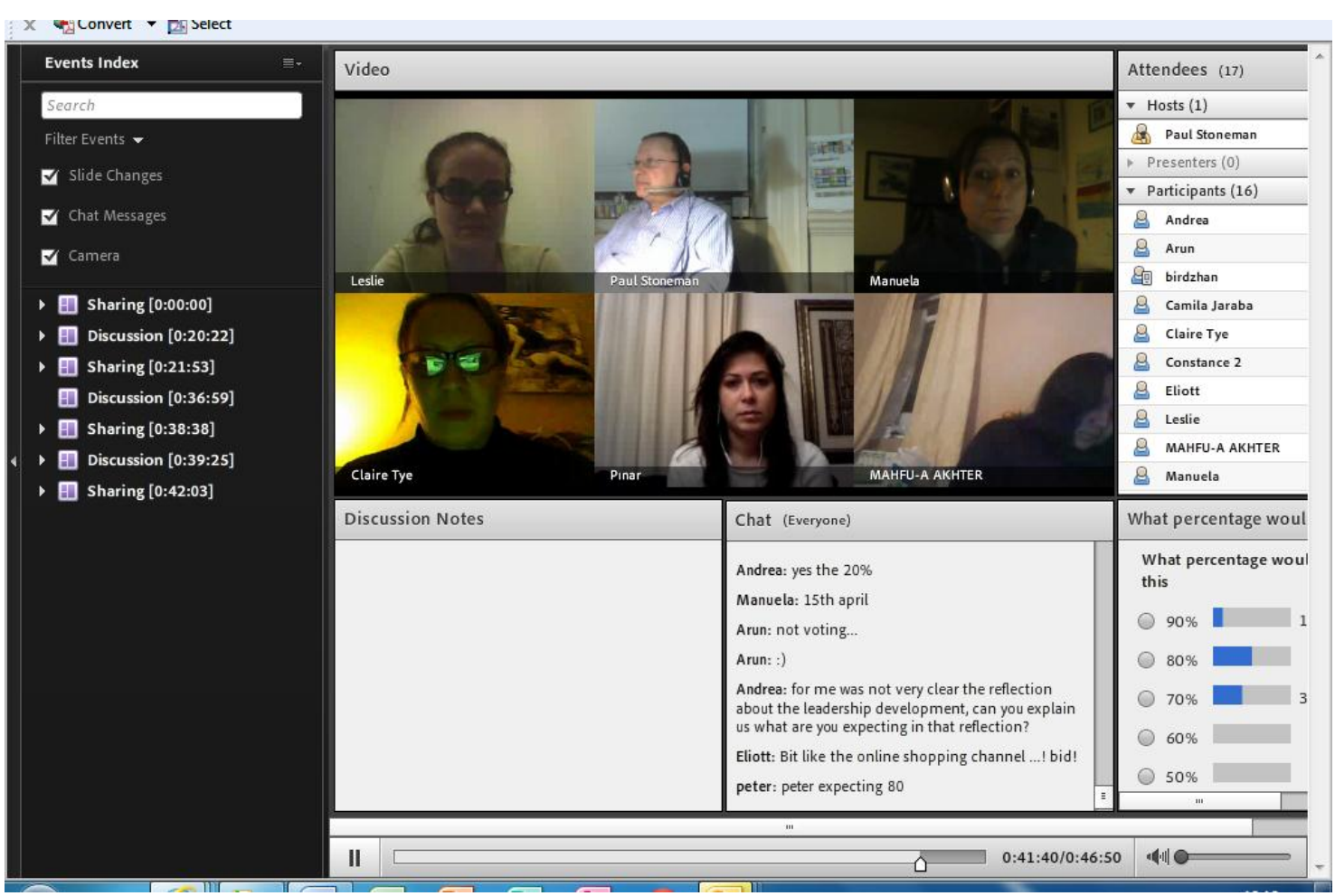

- Video and Audio features: The person hosting the webinar can enable their webcam to allow all participants to see the online session in real-time. The host can also enable each participant's webcam individually - so that they may also be seen by all participants if they so wish. The same facility also applies to audio, although most 
users prefer to click the 'hands-up' icon to show they wish to speak to avoid constant background chatter.

- Text Chat: All participants have access to the text based chat facility, which again is in real-time. This is shown in the middle column (Chat - Everyone) in Figure 1 above.

- Content: The host can share content in real-time. This includes PowerPoint slides, documents, applications, or they can mirror whatever is on their desktop. The host can individually allow participants to be co-presenters or to share their own content.

Figure 2: Screenshot of sharing content in Adobe Connect Webinar (March 2013)

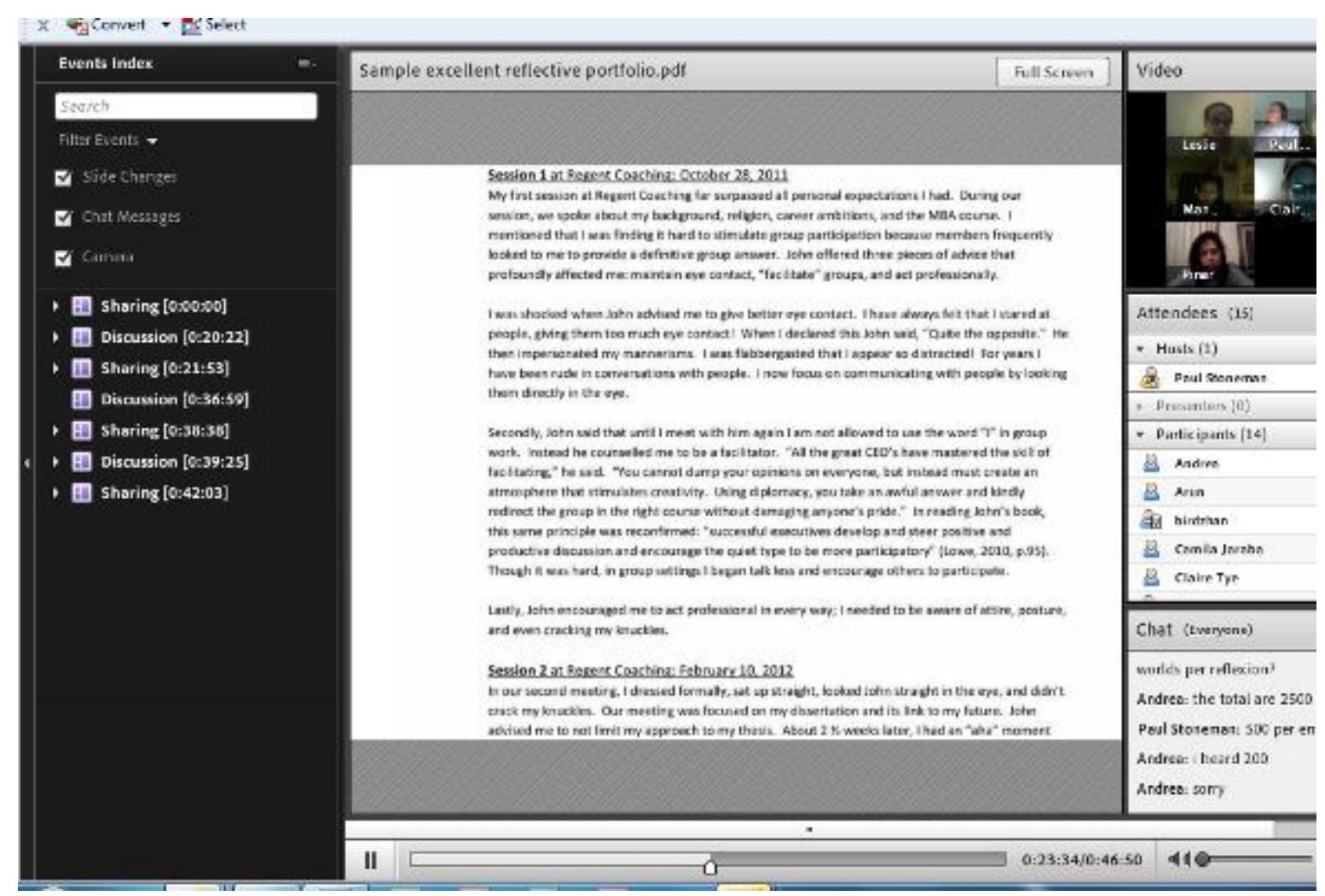

All the features listed above are real-time and synchronised. The entire webinar can also be recorded in this synchronised fashion and stored on the Adobe server for access/playback by anyone that the host provides with the URL.

\section{How does one access it?}

All that is required is a device (e.g.: PC, laptop, iPhone/iPad, Android mobile) and access to the Internet - no software needs to be installed except for a free 'app' for mobile devices.

The host presenter requires a software license which includes a login and password to the Adobe Connect server in order to set up a webinar online meeting room. A webinar can be set up in just a few keyboard clicks. All that is required is to give the webinar a "specific name", as well as a date/time and deciding whether the participants' access should be open access or password protected. The system returns a URL which can then be sent to desired participants. The whole process takes about a minute. 
Participants simply click the URL at the designated time and enter either as a guest or using the password provided by the host presenter.

\section{How can it be used for Teaching and Learning?}

Almost anything you can do in a classroom you can do via Adobe Connect online, PLUS you can have all of this available for participants who could not attend at the designated time to view later, or for those who did attend to recap on what happened.

I have used it for a number of pilot sessions:

- An interactive show and tell for academics - a kind of 'webinar about what you can do with webinars' both real-time and for later playback.

- Running an interactive workshop with a number of students to discuss the requirements for an upcoming piece of coursework. This involved presenting examples of good work and students asking questions using both the chat and audio facilities. Both full-time and part-time students joined the session.

\section{What other uses could it be put to?}

The limit is one's imagination. Here are a couple of suggestions that have been put to me:

- Recording an introduction to a course using PowerPoint slides with audio (as if it were a one-to-many lecture) so that it can be used for distance or partner students to view as needed.

- Integrating traditional students with part-time students by using it in the classroom in real-time.

- Programme or course team meetings for sharing materials or practice - perhaps including overseas collaborative partner tutors.

\section{What are the downsides?}

One needs a license, which costs money, and, whilst this can be shared, only one person can be running a webinar using that licence at any one time. Additionally, the host presenters need some initial training - maybe an hour, but once trained, Adobe Connect is very simple to use.

It could be argued that students may deliberately not engage if they can look at the whole session in playback later. Sweeney (2009) mentions that it is sometimes difficult to agree a time for all participants to engage. However, the record features of Adobe Connect alleviate this problem somewhat. Sweeney (op. cit.) also mentions technical problems, although the author's experience is that Adobe Connect specifically is very simple to use for presenters and participants.

It is thought that the use of webinars wouldn't be a wise decision for highly standardized, strictly planned and low-feedback courses and lectures (Moscow State University 2013). Also, if it is to be truly interactive, it becomes difficult to manage with very large numbers of participants.

Therefore it is important to recognise that pre-planning is critical to a webinar's success. 
'Giving an effective webinar requires some presentation redesign and technology skills that you don't necessarily need in a face-to-face presentation. A great speaker in a face-to-face environment can easily crash and burn in a webinar setting if he or she isn't prepared for theunique challenges and needs of that environment' (Mohorovicic 2011:1272).

\section{What is the student experience?}

In an online survey conducted with a sample of 215 students from several faculties in Croatia (Mohorovicic 2011:1273), it was found that:

'most of the students (89\%) consider that implementation of webinars in higher education would be useful and $70 \%$ of students believe that webinars, along with traditional teaching in classroom, will become common at universities. $55 \%$ of students think that [a] webinar can be [as] effective as face-to-face teaching in classroom. Opposed to that, $32 \%$ of students consider that their concentration on [a] lecture would be impaired while attending the lecture through webinar.'

The trial suggests that there is a high level of acceptance. One comment from a full-time student on the chat facility was 'we should run all our classes like this' as he was sitting at home eating his dinner.

\section{Future Plans}

The use of Adobe Connect to enhance engagement will be extended and used by other course leaders during the new academic year. Student feedback will be monitored through liaison meetings with the hope that there is an improved perception of engagement with tutors.

\section{References}

Mohorovicic, S., Lasic-Lazic J. and Strcic V. (2011). "Webinars in higher education." MIPRO, Proceedings of the 34th International Convention. IEEE 2011.

Moscow State University (2013). [Online]. Available at http://titova.ffl.msu.ru/webinars2.html. (Accessed 25/4/13).

Sweeney, S. (2009) Internationalisation and the use of electronic media in teaching and assessment. Live webinars and audio feedback: apparent benefits and drawbacks. HEA Journals Volume 2, Issue 1, July 2009.

\section{Author Biography}

Paul Stoneman is a principal lecturer and programme leader for the Masters of Business Administration. Before joining the University of Greenwich, Paul Stoneman qualified as an Engineer and spent many years in business within global blue chip organisations with management responsibilities for service operations, sales, marketing, training, business management and international business development across Europe, the Middle East and the USA. Paul has a Master's (MA Education-eLearning) which is an area of continuing research. 